\title{
Modulation of Renal Blood Flow and Vascular Tone by Neuronal Nitric Oxide Synthase-Derived Nitric Oxide
}

\author{
Noboru Toda ${ }^{a}$ b Tomio Okamura ${ }^{a}$ \\ a Department of Pharmacology, Shiga University of Medical Science, Otsu, and b Toyama Institute for \\ Cardiovascular Pharmacology Research, Osaka, Japan
}

\section{Key Words}

Nitric oxide $\cdot$ Nitric oxide synthase $\cdot$ Neuronal nitric oxide synthase $\cdot$ Nitrergic nerve $\cdot$ Renal blood flow $\cdot$ Regional blood flow $\cdot$ Renal artery $\cdot$ Sympathetic nerves $\cdot$ Vascular innervation $\cdot$ Vascular tone

\begin{abstract}
Nitric oxide (NO) formed via neuronal nitric oxide synthase (nNOS) in renal vasculature and tissues and in the brain plays an important role in controlling renal hemodynamics, renal function, and systemic blood pressure. Activation of parasympathetic nitrergic nerves innervating renal vasculature contributes to vasodilatation in renal arteries and pre- and postglomerular arterioles, an increase in renal blood flow, and a decrease in vascular resistance. NO released from autonomic nitrergic nerves interferes with the release of norepinephrine from adrenergic nerve terminals or the amine actions on smooth muscle. The pre- or postjunctional mechanisms of $\mathrm{NO}$ actions participate in vasodilatation through a diminution of sympathetic vasoconstrictor influence. On the other hand, NO from neurons in the brain acts on the paraventricular nucleus of the hypothalamus and the rostral ventrolateral medulla and inhibits the central sympathetic nerve activity to the kidney, leading to renal vasodilatation and increased renal blood flow. The present article summarizes in-
\end{abstract}

formation concerning the renal blood flow and vascular tone through nNOS-derived NO produced in peripheral autonomic nerves and the brain. The nNOS-derived NO-cyclic GMP pathway would be an important target for the treatment of renal circulatory dysfunction and chronic kidney disease.

Copyright $\odot 2010$ S. Karger AG, Basel

\section{Introduction}

'Endothelium-derived relaxing factor', discovered by Furchgott and Zawadzki [1], was identified as nitric oxide (NO) $[2,3]$. NO-synthesizing enzyme was first isolated from brain tissues [4], and its presence was immunohistochemically detected in various regions of the brain and peripheral neurons [5]. Functional roles of NO derived from neuronal NO synthase (nNOS) have been determined in the central nervous system and autonomic and sensory nerves. Later, this isoform of NO synthase (NOS) was found also in the kidney $[6,7]$ and skeletal muscle.

Endothelial NOS (eNOS)-derived NO has been recognized to play important roles in controlling renal hemodynamics, including increases in the renal plasma flow and pre- and postglomerular arteriolar dilatation. Im- 
pairment of this system leads to kidney dysfunction and systemic hypertension [8]. NO formed via nNOS in the parasympathetic and nitrergic nerves and nonneuronal tissues such as the glomeruli and tubules also contributes to the regulation of renal blood flow and kidney function. Monkey and canine renal arteries are innervated by autonomic nitrergic nerves, which play an important role in eliciting vasodilatation mediated by NO [9]. Renal sympathetic nerve functions are regulated centrally and peripherally by neurogenic NO. A deficiency of nNOSderived NO plays a role in chronic kidney diseases [10]. Information obtained from experimental animals concerning the role of nNOS-derived NO in renal circulatory regulation and the interaction between hypertension and renal function is insufficient to extrapolate the data to humans and patients with kidney diseases or hypertension.

The present review describes the current state of knowledge concerning the control of renal blood flow and vascular tone by nNOS-derived NO and its interaction with renal sympathetic nerve activity in experimental animals and humans. There is currently a shortage of research in this field and thus future investigations need to be encouraged to make up for this deficit.

\section{NO-Cyclic GMP Pathway}

$\mathrm{NO}$ is produced when L-arginine is transformed to Lcitrulline through catalysis by NOS in the presence of oxygen and cofactors, including calmodulin and tetrahydrobiopterin $\left(\mathrm{BH}_{4}\right) . \mathrm{Ca}^{2+}$ is required for the activation of nNOS [4] and eNOS (NOS III), but not of inducible NOS (iNOS; NOS II). nNOS, mostly a soluble enzyme, is constitutively expressed in the brain [11], peripheral nerves and kidneys. nNOS specific for the kidney has been cloned and termed nNOS-1 [12]. eNOS is also constitutively expressed, mostly in particulate fractions of the endothelial cell. iNOS is not constitutively expressed but is induced mainly in macrophages in response to bacterial lipopolysaccharide and cytokines. The synthesis of NO by these NOS isoforms is inhibited by L-arginine analogs, including $\mathrm{N}^{\mathrm{G}}$-monomethyl-L-arginine (L-NMMA), $\mathrm{N}^{\mathrm{G}}$ nitro-L-arginine (L-NA), L-NA methylester (L-NAME) and asymmetric dimethylarginine. 7-Nitroindazole (7NI) [13] and S-methyl-L-thiocitrulline (SMTC) [14] are selective nNOS inhibitors. SMTC inhibited L-citrulline formation from $\mathrm{L}$-arginine in rat brain slices with an $\mathrm{IC}_{50}$ value of $0.31 \mu \mathrm{M}$ and aortic ring relaxation with an $\mathrm{IC}_{50}$ value of $5.4 \mathrm{mM}$, suggesting 17 -fold greater selectivity for
nNOS compared to eNOS in rats [14]. Whether the doses of inhibitors are selective for nNOS has been evaluated in in vivo studies by an absence of systemic hypertensive effects $[15,16]$. Aminoguanidine has long been known to be a selective iNOS inhibitor. Nitro compounds, including nitroglycerin and sodium nitroprusside, are capable of liberating NO, so they are called NO donors.

Endogenous NO and NO donors cause vasodilatation, decreased vascular resistance, lowered blood pressure, inhibition of platelet aggregation and adhesion, inhibition of leukocyte adhesion and transmigration and reduced vascular smooth muscle proliferation. NO activates soluble guanylyl cyclase and produces cyclic GMP from GTP in smooth muscle cells and neurons. Oxyhemoglobin scavenges $\mathrm{NO}$, and $1 \mathrm{H}[1,2,4]$ oxadiazolo[4,3-a] quinoxalin-1-one [17] inhibits guanylyl cyclase activity. Accumulation of cyclic GMP causes activation of cyclic GMP-dependent protein kinases, which in turn causes a reduction of intracellular $\mathrm{Ca}^{2+}$ and a decrease in the sensitivity of contractile elements to $\mathrm{Ca}^{2+}$, resulting in vascular smooth muscle relaxation [18]. Feil et al. [19] summarized the information concerning cyclic GMP-dependent protein kinases as important downstream effectors of NO and cyclic GMP in the nervous system.

Histochemical studies have demonstrated the presence of reduced nicotinamide adenine dinucleotide phosphate (NADPH)-positive or nNOS-immunoreactive nerve fibers innervating the vascular wall. Nonadrenergic noncholinergic inhibitory responses to autonomic nerve stimulation are mainly mediated through NO synthesized by nNOS; NO plays a crucial role as a neurotransmitter from the peripheral efferent nerves in cerebral and peripheral blood vessels and microvasculature $[5,20,21]$. nNOS-positive neurons are also found in many discrete cell groups throughout the brain $[5,22]$. In the hypothalamus, the most striking groups of nNOS-immunoreactive neurons were found within the paraventricular and supraoptic nuclei. Areas of the brainstem with nNOS-containing neurons include the nucleus tractus solitarius, ventrolateral medulla and raphe nuclei [23]. There are nNOS-containing neurons in sympathetic preganglionic neurons in the spinal cord [24]. Afferent nitrergic nerves control some aspects of sensory information processing. Many of the homeostatic actions of spinal afferents are brought about by the release of transmitters [NO and calcitonin gene-related peptide (CGRP)] from their peripheral endings [25].

In the brain, $\mathrm{NO}$ functions mainly as a neuromodulator. NO signaling appears to be essential for neural plasticity, that is, long-term potentiation in the hippocampus 
and long-term depression in the cerebellum. Glutamate participates mainly in synaptic interactions, but with the help of NO, the strength of the excitatory input might be nonsynaptically signaled to the surrounding monoaminergic neurons in the brain. $\mathrm{N}$-methyl-D-aspartate receptor activation increases $\mathrm{Ca}^{2+}$ influx and intracellular $\mathrm{Ca}^{2+}$ concentrations, resulting in the production of $\mathrm{NO}$, which then diffuses to adjacent nerve terminals to modulate neurotransmitter release [26].

Under pathological conditions (e.g. during inflammation), high levels of NO are produced after iNOS expression is induced, mainly in macrophages. NO possesses the protective/destructive duality inherent in every other major component of the immune response. This labile molecule exerts beneficial effects by acting as an antibacterial, antiparasitic, antiviral or tumoricidal agent; on the other hand, high levels of NO, if uncontrolled, cause detrimental effects that are produced because NO reacts with concomitantly produced superoxide anions, thereby generating highly toxic compounds such as peroxynitrite and hydroxyl radicals.

\section{Effects of Neurogenic NO on Renal Vascular Function and Blood Flow}

\section{Studies on Isolated Renal Arteries and Arterioles from}

Experimental Animals

The functioning of nitrergic nerves was first demonstrated in isolated dog cerebral arteries treated with the $\alpha_{1}$-adrenoceptor antagonist prazosin and vasodilated in response to transmural electrical nerve stimulation or nicotine $[27,28]$. Similar vasodilatory responses to perivascular nerve stimulation were also demonstrated in dog and Japanese monkey renal arteries [9]. Nicotine-induced relaxations in these tissues were abolished by treatment with L-NA and hexamethonium, and L-arginine, but not D-arginine, reversed the effect of the NOS inhibitor (fig. 1). Histochemical studies demonstrated perivascular nerves containing NADPH diaphorase and NOS immunoreactivity in the renal arteries. There is an intimate spatial relationship between nNOS-positive cells and preglomerular afferent arterioles [29]. In the rat kidney, NADPH-diaphorase-positive and NOS immunoreactive neurons were seen at the renal hilus close to the renal artery and along the interlobar vasculature; postganglionic NOS-containing neurons projected into the wall of the renal pelvis and/or to the interlobar arteries extending to the arcuate arteries and to the beginning of the afferent arterioles [30]. Vasa recta in the rat kidney

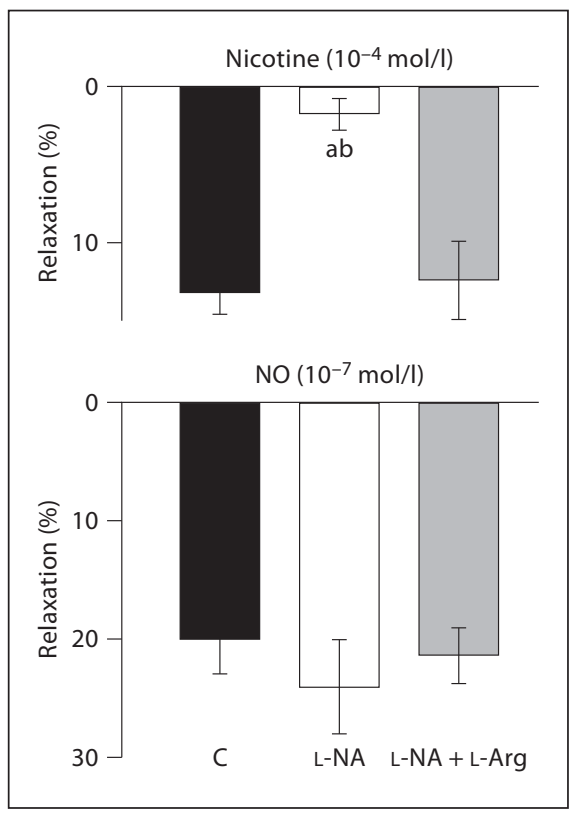

Fig. 1. Relaxation of monkey renal arteries in response to nicotine, which stimulates the release of NO from nitrergic nerves (upper panel), and to exogenous NO (lower panel), as affected by L-NA and L-arginine (L-Arg). The arteries were treated with prazosin to suppress the response to neurogenic norepinephrine. ${ }^{\mathrm{a}, \mathrm{b}}$ Significantly different from control (C) and L-NA + L-Arg, respectively. Reproduced with permission from Okamura et al. [9].

were found to express mRNA for nNOS and eNOS [31]. In isolated rabbit renal arteries without an intact endothelium, L-NAME enhanced the vasoconstrictor response to electrical nerve stimulation but did not affect the response to norepinephrine; NOS-containing nerves were located on the vascular adventitia [32]. The authors suggested a presynaptic inhibitory effect of neurogenic NO acting on perivascular adrenergic vasoconstrictor nerves [32]; however, this cannot be verified without knowing whether the release of neurogenic norepinephrine is attenuated by $\mathrm{NO}$ donors in tissues with inactivated NOS. A postsynaptic site of inhibition by NO may also be a possibility [21]

In isolated rabbit renal afferent arterioles constricted by phenylephrine, nicotine-induced dilatation was abolished by L-NA or 7-NI, and L-arginine restored the response, suggesting the involvement of NO liberated from nitrergic nerves in the vasodilatory response [33]. Using the blood-perfused juxtamedullary nephron technique in rats, Ichihara et al. $[34,35]$ noted that superfused SMTC $(10 \mu \mathrm{M})$ decreased afferent and efferent arteriolar diameters. In addition, Ichihara et al. [35] provided evidence 
suggesting that chronic angiotensin (ANG) II infusion reduces the ability of nNOS-derived NO to counteract the afferent arteriolar response to increased distal tubular flow. In spontaneously hypertensive rats, tempol increased afferent arteriolar diameters and enhanced afferent arteriolar constrictor responses to SMTC $(10 \mu \mathrm{M})$, whereas it did not affect the vasodilator response; the vasoconstrictor response to SMTC was not enhanced in Wistar-Kyoto rats [36]. Superoxide anions appear to inhibit the vasodilatory effects of NO formed via nNOS in afferent arterioles in spontaneously hypertensive rats. Histochemical and biochemical studies demonstrated that rats with desoxycorticosterone acetate (DOCA)-salt-induced hypertension had reduced nNOS expression in the macula densa and decreased NO production in the juxtaglomerular apparatus compared to controls; the diameter of the afferent arterioles was smaller in DOCA rats compared to control rats [37]. The authors suggested that the afferent arteriolar diameter is regulated by nNOS-derived NO in the macula densa in DOCA-salt-hypertensive rats [37].

In summary, isolated renal arteries and arterioles respond to electrical nerve stimulation or nicotine with relaxations that are mediated by NO derived from nitrergic nerves. Histochemical studies indicate the presence of $\mathrm{NO}$-containing neurons in the arterial and arteriolar wall. Blood-perfused afferent and efferent arterioles appear to tonically liberate NO from perivascular nerves to increase medullary blood flow. Nitrergic vasodilator neurons are likely to play an important role in the control of renal arterial and arteriolar tone and blood flow.

\section{In vivo Studies}

There have been a number of reports demonstrating decreased renal blood flow, increased renal vascular resistance and elevated systemic blood pressure after treatment with nonselective NOS inhibitors in anesthetized and conscious rats [38-41]. Impairment of NO production via eNOS blockade is involved in these hemodynamic changes; however, the role of NO derived from nNOS in the control of the renal circulation has not been determined.

Renal plasma flow was decreased and renal vascular resistance was increased after intra-aortic administration of the selective nNOS inhibitor SMTC $(0.05 \mathrm{mg} / \mathrm{kg}$, a dose that was not associated with an increase in systemic blood pressure) to a similar extent in control and hyperglycemic streptozotocin-diabetic rats; SMTC reduced the glomerular filtration rate to a near-normal level in hyperfiltering diabetic rats, whereas much higher doses were required to decrease the glomerular filtration rate in control rats, suggesting a greater effect of the
nNOS inhibitor on preglomerular vascular tone [16]. In addition, immunohistochemistry revealed increased numbers of nNOS-positive cells in the macula densa of diabetic rats. nNOS was postulated to play a major role in the pathogenesis of renal hemodynamic changes early in the course of diabetes. Walkowska et al. [42] provided evidence that adequate perfusion of the medulla is largely dependent on nNOS-derived NO, whereas NO generated by nNOS and other isoforms is responsible for adequate circulation within the cortex in rats. nNOS inhibition reduced renal blood flow in Brown Norway rats, which often show exaggerated responses to NOS [43]. Intrarenal administration of SMTC $(0.3 \mathrm{mg} / \mathrm{h})$ caused a decrease in the renal plasma flow in rats, which was prevented by treatment with candesartan [44], suggesting that ANG II type 1 receptor-mediated renal arteriolar constriction is counterbalanced by NO formed via nNOS. In anesthetized wild-type and nNOS knockout mice, LNAME increased blood pressure and decreased blood flow in the renal cortex and medulla, whereas blood pressure and renal blood flow were unaffected after L-NAME administration to eNOS knockout mice. Intravenous infusion of ANG II decreased renal cortical blood flow in wild-type, eNOS knockout and nNOS knockout mice and in wild-type mice treated with L-NAME; however, ANG II infusion increased medullary blood flow in wildtype and eNOS knockout mice, and this increase was not observed in nNOS knockout mice [45]. It appears that NO formed via eNOS regulates basal blood flow in the mouse renal cortex and medulla, while NO from nNOS mediates an increase in medullary blood flow in response to ANG II. Intravenous administration of SMTC $(1 \mathrm{mg} / \mathrm{h})$ decreased renal plasma flow to a similar extent in transgenic rats with inducible ANG II-dependent malignant hypertension and in control rats; the COX-2 inhibitor nimesulide, during simultaneous infusion of SMTC, decreased renal plasma flow in hypertensive rats but not in normotensive rats, suggesting that both nNOS-derived $\mathrm{NO}$ and COX-2 metabolites exert renal vasodilator influences in malignant hypertensive rats [46].

Table 1 summarizes the data concerning the roles of NO derived from nNOS in renal hemodynamics in rats and mice. Decreases in renal plasma flow, medullary blood flow and cortical blood flow by treatment with a variety of selective nNOS inhibitors in vivo, together with the vasodilator effects of nitrergic nerve stimulation in isolated renal arteries and arterioles, lead us to speculate that the tonic activation of perivascular nitrergic nerves contributes to renal arterial and arteriolar dilatation and increased blood flow. 
Table 1. Role of nNOS-derived NO in renal blood flow in vivo

\begin{tabular}{|c|c|c|c|c|c|}
\hline Reference & Animals & Treatment & Response & nNOS & Comment \\
\hline $\begin{array}{l}\text { Komers et al. } \\
{[16], 2000}\end{array}$ & rats and DM rats & SMTC & $\begin{array}{l}\text { RPF decrease in both } \\
\text { nNOS increase in DM rats }\end{array}$ & nNOS-positive cells & role of nNOS-NO \\
\hline $\begin{array}{l}\text { Cervenka et al. } \\
{[44], 2001}\end{array}$ & rats & $\begin{array}{l}\text { SMTC } \\
\text { Cande + SMTC } \\
\text { ANG II + SMTC }\end{array}$ & $\begin{array}{l}\text { RPF decrease } \\
\text { RPF no change } \\
\text { RPF no change }\end{array}$ & $\begin{array}{l}\text { nNOS activity and } \\
\text { mRNA increase by } \\
\text { AT1A-KO [47] }\end{array}$ & $\begin{array}{l}\text { role of nNOS-NO } \\
\text { nNOS-NO counteracts ANG II } \\
\text { ANG II impairs NO release }\end{array}$ \\
\hline $\begin{array}{l}\text { Walkowska } \\
\text { et al. [42], } \\
2004\end{array}$ & $\begin{array}{l}\text { rats } \\
\text { rats, denervation }\end{array}$ & $\begin{array}{l}7-\mathrm{NI} \\
7-\mathrm{NI}\end{array}$ & $\begin{array}{l}\mathrm{M} \text { and } \mathrm{C} \text { flow decrease } \\
\text { no change in flow }\end{array}$ & & $\begin{array}{l}\text { role of nNOS-NO } \\
\text { sympathetic inhibition by NO }\end{array}$ \\
\hline $\begin{array}{l}\text { Mattson and } \\
\text { Meister [45], } \\
2005\end{array}$ & $\begin{array}{l}\text { wild-type and eKO } \\
\text { mice } \\
\text { nKO mice }\end{array}$ & $\begin{array}{l}\text { ANG II } \\
\text { ANG II }\end{array}$ & $\begin{array}{l}M \text { flow increase } \\
\text { no change in flow }\end{array}$ & nNOS null & $\begin{array}{l}\text { no role of eNOS-NO in } \mathrm{M} \text { flow } \\
\text { role of nNOS-NO in M flow }\end{array}$ \\
\hline $\begin{array}{l}\text { Patterson et al. } \\
{[46], 2008}\end{array}$ & hypertensive rats & SMTC & RPF decrease & $\begin{array}{l}\text { nNOS-positive cell increase } \\
\text { in HT [48] }\end{array}$ & role of nNOS-NO \\
\hline $\begin{array}{l}\text { Wang and } \\
\text { Cupples [43], } \\
2009\end{array}$ & brown Norway rats & VNIO & renal blood flow decrease & & role of nNOS-NO \\
\hline $\begin{array}{l}\text { Abram et al. } \\
{[50], 2001}\end{array}$ & $\begin{array}{l}\text { pregnant rats } \\
\text { virgin rats }\end{array}$ & $\begin{array}{l}\text { 7-NI } \\
7 \text {-NI }\end{array}$ & $\begin{array}{l}\text { RPF decrease } \\
\text { RPF no change }\end{array}$ & nNOS protein increase in pregnancy [49] & $\begin{array}{l}\text { role of nNOS-NO } \\
\text { no role of nNOS-NO }\end{array}$ \\
\hline $\begin{array}{l}\text { Ratliff et al. } \\
\text { [51], 2009 }\end{array}$ & newborn swine & & $\begin{array}{l}\text { nNOS gene upregulation } \\
\text { in PRVs }\end{array}$ & age-dependent nNOS activity & nNOS-NO counteracts ANG II \\
\hline
\end{tabular}

$\mathrm{DM}=$ Diabetes mellitus; RPF = renal plasma flow; AT1A-KO = ANG II type 1A receptor gene knockout; nNOS-NO = nNOS-derived NO; eNOS$\mathrm{NO}=\mathrm{e}-\mathrm{NOS}$-derived NO; Cande = candesartan; $\mathrm{M}$ flow = medullary blood flow; $\mathrm{C}$ flow = cortical blood flow; $\mathrm{eKO}=\mathrm{eNOS} \mathrm{knockout} ; \mathrm{nKO}=\mathrm{nNOS}$ knockout; HT = hypertension; VNIO = vinyl-L-N5-(1-imino-3-butenyl)-L-ornithine; PRV = preglomerular resistance vessels.

Infusion of 7-NI ( $2 \mathrm{mg} / \mathrm{kg} / \mathrm{h}$ for $60 \mathrm{~min})$ to pregnant rats at day 16 of gestation decreased renal plasma flow without a change in mean arterial pressure, whereas nNOS inhibition had no effect on renal plasma flow in virgin rats, suggesting that nNOS may play a role in mediating the renal hemodynamic changes that occur during pregnancy [50]. nNOS, renin and ANG II type 2 receptor expression in afferent, interlobar and arcuate arterioles were upregulated in newborn swine (7 and 21 days of age) and decreased with age to reach the lowest levels in adult swine; in contrast, eNOS and ANG II type 1 receptor expression was downregulated at birth [51]. The nNOS isoform may be responsible for counteracting ANG II-induced vasoconstriction in immature porcine renal resistance vasculature.

The findings described so far demonstrate the physiological role of nNOS-derived NO as a vasodilator in renal hemodynamics in various mammals. In contrast, Kakoki et al. [52] found evidence suggesting that nNOS does not regulate basal blood flow in the renal cortex or medulla in rats, despite the observation that a consider- able portion of NO in the renal interstitial space is produced by nNOS. The reason for the discrepancy is unclear, but it may involve differences in the nNOS inhibitors employed, the doses of nNOS inhibitors used, the route of administration or the duration of administration.

The mechanisms underlying neurogenic vasodilatation in rats and possibly mice are controversial; the vasodilator neurotransmitters in mesenteric arteries are CGRP [53], NO [54] or NO + CGRP [55]. In contrast, in other mammals, such as dogs, cows and Japanese monkeys, NO has been shown to play a major role in neurogenic vasodilatation $[21,56]$.

The nNOS-derived NO release is interconnected with short-term changes in local blood flow, blood pressure dynamics, urine production and renin release. It has been estimated that NO diffuses in tissues from 0.2 to $0.25 \mathrm{~mm}$ in 5-10 s [57], well within the range generally considered to be the tissue half-life. Such a short half-life may play a role in modulating $\mathrm{NO}$ actions on the renal circulation. 


\section{Studies on Human Tissues}

There was found to be an intimate spatial relationship between nNOS-positive cells and renin-containing preglomerular afferent arterioles in various mammals, including humans; the efferent arteriole endothelium contained nNOS and eNOS, and renal nerves containing nNOS were found in perivascular connective tissue and near the pelvic epithelium [29]. In recipients of cadaveric renal allografts with sustained kidney injury, urinary nitrogen oxide excretion was lower than in those with recovering renal function; $\mathrm{nNOS}$ staining was rarely observed in the macula densa of allograft biopsies from subjects with kidney injury, and eNOS expression was decreased to a greater extent in peritubular capillaries of these subjects [58]. Diminished NO generation by injured endothelium and loss of macula densa nNOS may impair the vasodilatory capacity of the renal vasculature.

In healthy volunteers, oral $\mathrm{BH}_{4}$ given over 3 days $(800$ $\mathrm{mg}$ /day) increased serum cyclic GMP and nitrogen oxide levels and ameliorated the depressive effects of L-NAME on the glomerular filtration rate; the decrease in renal plasma flow and increase in blood pressure induced by L-NAME were not altered by treatment with $\mathrm{BH}_{4}$ [59]. Based on increased plasma renin activity by $\mathrm{BH}_{4}$ infusion, $\mathrm{BH}_{4}$-induced stimulation of $\mathrm{nNOS}$ in the macula densa was suggested.

\section{Interactions between Neurogenic NO and Sympathetic Nerves in Renal Blood Flow}

\section{Peripheral Sites of Action}

In anesthetized dogs, intrarenal infusion of L-NA enhanced the renal vasoconstriction and increases in norepinephrine secretion induced by renal nerve stimulation, suggesting that endogenous NO may play a role in presynaptically inhibiting renal noradrenergic nerve function [60]. However, whether NO is derived from either nitrergic nerves or endothelial cells or both has not been determined. In anesthetized rats, renal nerve denervation increased cortical blood flow but not medullary blood flow; the renal denervation only opposed a decrease in cortical blood flow caused by L-NAME but restored decreases in both cortical and medullary blood flow caused by intraperitoneal 7-NI $(12.5 \mathrm{mg} / \mathrm{kg})$ [42]. There seems to be an interaction between nNOS and renal nerves with regard to medullary blood flow. Electrical stimulation of renal nerves in rats decreased inner medullary blood flow to a lesser extent than total renal blood flow and outer medullary blood flow; treatment with
SMTC $(20 \mu \mathrm{g} / \mathrm{kg} / \mathrm{min}$, i.v. $)$ enhanced the stimulation-induced decrease in inner medullary blood flow, without affecting the response of renal blood flow or inner medullary blood flow [61]. It appears that NO generated in the kidney buffers the intrarenal vasoconstriction triggered by renal nerve stimulation and that NO derived from nNOS plays an important role in the control of inner medullary perfusion. From studies using wild-type, nNOS-deficient and eNOS-deficient mice as well as nonselective NOS and selective nNOS inhibitors in isolated perfused kidneys, Stegbauer et al. [62] provided evidence suggesting that NO attenuates ANG II-induced increases in renal vascular resistance and norepinephrine release from sympathetic nerves; these effects are mediated by eNOS and nNOS, but NO derived from eNOS dominates. NO appears to prejunctionally modulate adrenergic nerve function. However, there are a number of reports from studies in dog, rabbit and rat arteries suggesting a postsynaptic mechanism of $\mathrm{NO}$ action; that is, NO opposes the contracting action of norepinephrine at the postjunctional smooth muscle, as a physiological antagonist [21]. Possible sites of action of endogenous $\mathrm{NO}$ on adrenergic nerves (pre- and postjunctional sites) are shown in figure 2 .

\section{Central Sites of Action}

Using nNOS immunohistochemistry combined with pseudorabies virus tract tracing, Weiss et al. [63] found that nNOS-containing neurons are part of the renal sympathetic motor and sensory pathways in rat spinal cord and brain. Therefore, NO is expected to participate in renal afferent and efferent neurotransmission.

There is evidence suggesting that nNOS suppresses the sympathetic discharge generated before baroreflexmediated inhibition in Dahl salt-sensitive and salt-resistant rats fed either a regular-salt or a high-salt diet; this effect is enhanced by salt loading in both salt-resistant and salt-sensitive Dahl rats, and nNOS-mediated suppression of tonic peripheral sympathetic outflow is greatly enhanced in salt-sensitive hypertension [64]. Similar findings were obtained by Tandai-Hiruma et al. [65] by comparing the effect of SMTC (50 nmol infused over 2 min into the lateral ventricle) on the renal sympathetic nerve activity in hypertensive and normotensive Dahl rats. Hypertensive Dahl rats showed enhanced nNOS activity in the brainstem and increased numbers of nNOS neurons in several nuclei throughout the brainstem. In rats in which adenovirus vectors encoding nNOS were transfected into the paraventricular nucleus of the hypothalamus, there was a robust increase in staining of 
Fig. 2. Possible sites of central and peripheral actions of nNOS-derived NO in counteracting the function of sympathetic nerves innervating a renal artery. The sites of ANG II actions are also included. Dotted lines denote inhibitory action. PVN = Paraventricular nucleus; NTS = nucleus tractus solitarius; RVLM = rostral ventrolateral medulla; $\mathrm{NE}=$ norepinephrine; $\alpha_{1}=\alpha_{1}$-adrenoceptor; $\mathrm{AT}_{1}=$ ANG II type 1 receptor.

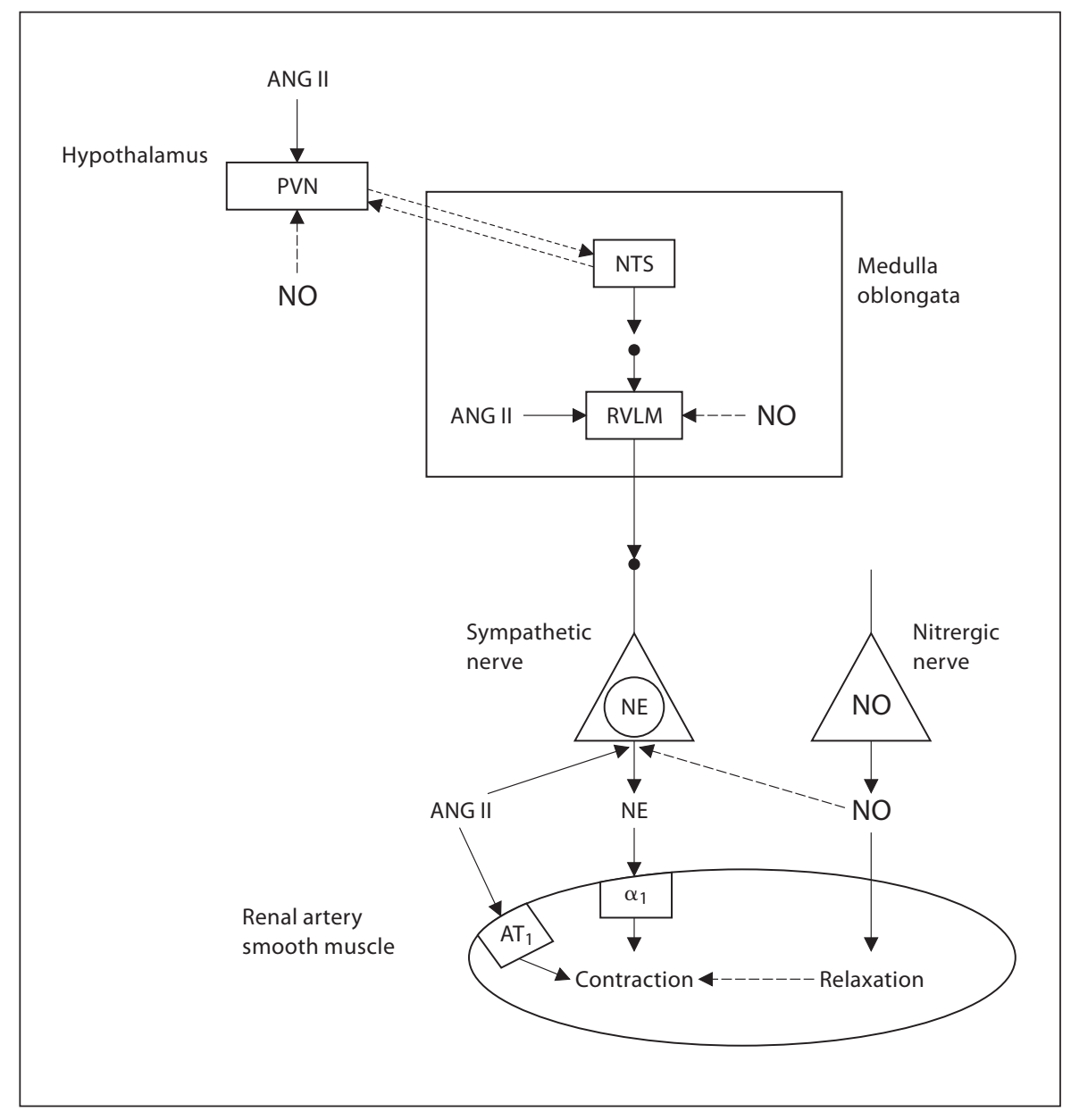

NADPH-diaphorase-positive cells on the side of gene transfer; in anesthetized rats, microinjections of $\mathrm{L}$ NMMA into the paraventricular nucleus increased renal sympathetic nerve discharge, blood pressure and heart rate, the effects that were enhanced in nNOS-transfected rats [66]. Overexpression of nNOS within the paraventricular nucleus appears to be responsible for increased suppression of sympathetic outflow. Intraventricular infusion of ANG II increased blood pressure, renal sympathetic nerve activity and norepinephrine release from the posterior hypothalamus and reduced the abundance of $\mathrm{nNOS}$ and IL-1 $\beta$ mRNA in the posterior hypothalamus, paraventricular nucleus and locus ceruleus, suggesting that decreased nNOS expression and NO production in the brain caused by ANG II results in greater sympathetic nerve activity and hypertension [67]. Microinjection of ANG II into the paraventricular nucleus increased renal sympathetic nerve discharge and blood pressure in rats, and these responses were enhanced by microinjection of
L-NMMA and blocked by losartan; the ANG II responses were potentiated by administration of antisense oligonucleotide to nNOS within the paraventricular nucleus and conversely attenuated by overexpression of nNOS; ANG II increased NO release in the same nucleus [68]. It appears that NO in the paraventricular nucleus, which is induced by ANG II type 1 receptor stimulation, in turn inhibits the ANG II-mediated increase in sympathetic nerve activity.

It was found that nNOS-positive cells in the paraventricular nucleus were fewer and nitrogen oxide release from the nucleus perfusate was lower in diabetic rats compared with control rats [69]. L-NMMA microinjected into the paraventricular nucleus produced an increase in renal sympathetic nerve activity and mean arterial pressure, and these responses were attenuated in rats with diabetes. Microinjection of sodium nitroprusside decreased sympathetic nerve activity and blood pressure; these responses to sodium nitroprusside were blunted in 
the diabetic rats [69]. Decreased NO generation and release in the paraventricular nucleus may contribute to the increased renal sympathetic neural activity observed in diabetes. Microinjections of resveratrol into the rostral ventrolateral medulla decreased blood pressure and renal sympathetic nerve activity in rats; pretreatment with LNAME or microinjection of Bay K8644, an agonist of $\mathrm{Ca}^{2+}$ channels, suppressed the effect of resveratrol, suggesting that $\mathrm{NO}$ synthesis and a decrease in $\mathrm{Ca}^{2+}$ influx may mediate the effect of resveratrol on blood pressure and renal sympathetic nerve activity [70]. Intravenous tempol reduced mean arterial pressure, renal sympathetic nerve activity and spontaneous discharge of neurons in the paraventricular nucleus of the hypothalamus and the rostral ventrolateral medulla in rats; pretreatment with the hydroxyl radical scavenger dimethyl sulfoxide attenuated the tempol-induced decreases in blood pressure and sympathetic nerve activity, but L-NAME had no effect [71]. Reduction of the influence of reactive oxygen species but absence of an increase in NO in those brain regions may participate in the effect of systemically administered tempol.

Taken together, these findings suggest that NO is able to restrain sympathetic drive in the brain (fig. 2). Central ANG II decreases nNOS expression and increases sympathetic outflow; overexpression of nNOS or supplementation of $\mathrm{NO}$ donors in the paraventricular nucleus and the rostral ventrolateral medulla seems to counterbalance the increased sympathetic nerve drive. Reactive oxygen species in the brain may also be involved in renal sympathetic activation.

\section{Summary}

Smooth muscle tone and contractility, except in vascular smooth muscle, are controlled by reciprocal dual innervation, sympathetic inhibitory and parasympathetic excitatory nerves; in contrast, vascular smooth muscle reactivity has been recognized to be regulated solely by sympathetic vasoconstrictor nerves. Parasympathetic NOmediated vasodilator innervation was first found in cerebral arteries, and this finding was extended to peripheral vasculatures, including the renal blood vessels. The present review summarizes the functional role of nitrergic nerves in the regulation of renal blood flow and in the inhibition of sympathetic vasoconstriction in the kidney. Electrical stimulation of perivascular nerves under $\alpha$-adrenoceptor blockade produces an $\mathrm{NO}$-mediated vasodilatation in isolated renal arteries and arterioles. In anesthetized animals, selective nNOS inhibitors decrease renal blood flow and increase renal vascular resistance, suggesting a tonic nitrergic nerve activation that is responsible for maintaining the increase in renal blood flow. Renal vasoconstriction via sympathetic nerve stimulation is reduced by NO derived from nitrergic nerves through decreased release of the transmitter norepinephrine or physiological antagonism by $\mathrm{NO}$ of the amine actions postsynaptically. On the other hand, NO liberated in the brain acts on the paraventricular nucleus of the thalamus and rostral ventrolateral medulla and interferes with the central sympathetic drive to the kidney. However, findings in healthy subjects and human tissues are still limited and conflicting. Insight into the role of nNOS-derived NO in autonomic nerves and the brain will provide us with a better understanding of renal hemodynamics and contribute to developing novel strategies for the treatment of renal circulatory disturbances and chronic kidney diseases.

\section{References}

\footnotetext{
Furchgott RF, Zawadzki JV: The obligatory role of endothelial cells in the relaxation of arterial smooth muscle by acetylcholine. $\mathrm{Na}-$ ture 1980;288:373-376.

2 Furchgott RF: Studies on relaxation of rabbit aorta by sodium nitrite: the basis for the proposal that the acid-activatable inhibitory factor from retractor penis is inorganic nitrite and the endothelium-derived relaxing factor is nitric oxide; in Vanhoutte PM (ed): Vasodilatation: Vascular Smooth Muscle, Peptides, Autonomic Nerve and Endothelium. New York, Raven, 1988, pp 401-414.
}

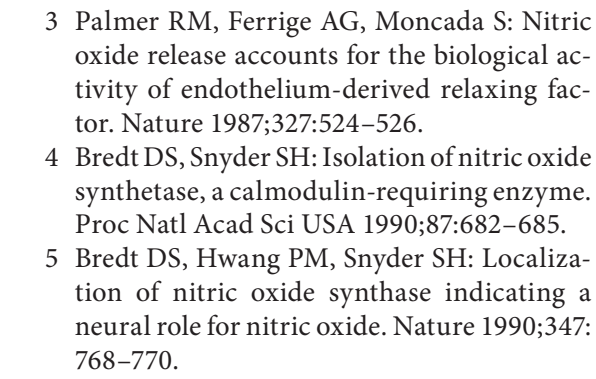
oxide release accounts for the biological ac tivity of endothelium-derived relaxing factor. Nature 1987;327:524-526. synthetase, a calmodulin-requiring enzyme. Proc Natl Acad Sci USA 1990;87:682-685. tion of nitric oxide synthase indicating a $768-770$.
-6 Wilcox CS, Welch WJ, Murad F, Gross SS, Taylor G, Levi R Schmidt HHHW: Nitric oxide synthase in macula densa regulates glomerular capillary pressure. Proc Natl Acad Sci USA 1992;89:11993-11997.

7 Mount PF, Power DA: Nitric oxide in the kidney: functions and regulation of synthesis. Acta Physiol (Oxf) 2006;187:433-446.

8 Zoccali C: The endothelium as a target in renal disease. J Nephrol 2007;20(12 suppl):S39S44.

9 Okamura T, Yoshida K, Toda N: Nitroxidergic innervation in dog and monkey renal arteries. Hypertension 1995;25:1090-1095. 
10 Baylis C: Nitric oxide deficiency in chronic kidney disease. Am J Physiol Renal Physiol 2008;294:F1-F9.

-11 Förstermann U, Pollock JS, Schmidt HH, Heller M, Murad F: Calmodulin-dependent endothelium-derived relaxing factor/nitric oxide synthase activity is present in the particulate and cytosolic fractions of bovine aortic endothelial cells. Proc Natl Acad Sci USA 1991;88:1788-1792.

12 Oberbäumer I, Moser D, Bachmann S: Nitric oxide synthase $1 \mathrm{mRNA}$ : tissue-specific variants from rat with alternative first exons. Biol Chem 1998;379:913-919.

$\checkmark 13$ Moore PK, Babbedge RC, Weallace P, Gaffen ZA, Hart SL: 7-Nitroindazole, an inhibitor of nitric oxide synthase, exhibits anti-nociceptive activity in the mouse without increasing blood pressure. Br J Pharmacol 1993;108: 296-297.

-14 Furfine ES, Harmon MF, Paith JE, Knowles RG, Salter M, Kiff RJ, Duffy C, Hazelwood R, Oplinger JA, Garvey EP: Potent and selective inhibition of human nitric oxide synthases. Selective inhibition of neuronal nitric oxide synthase by S-methyl-L-thiocitrulline and S-ethyl-L-thiocitrulline. J Biol Chem 1994; 269:26677-26683.

15 Beierwaltes WH: Macula densa stimulation of renin is reversed by selective inhibition of neuronal nitric oxide synthase. Am J Physiol 1997;272:R1359-R1364.

-16 Komers R, Lindsley JN, Oyama TT, Allison $\mathrm{KM}$, Anderson S: Role of neuronal nitric oxide synthase (NOS1) in the pathogenesis of renal hemodynamic changes in diabetes. Am J Physiol Renal Physiol 2000;279:F573-F583.

17 Garthwaite J, Southam E, Boulton CL, Nielsen EB, Schmidt K, Mayer B: Potential and selective inhibition of nitric oxidesensitive guanylate cyclase by $1 \mathrm{H}-[1,2,4]$ oxadiazolo[4,3-a]quinoxalin-1-one. Mol Pharmacol 1995;48:184-188.

18 Carvajal JA, Germain AM, Huidobro-Toro JP, Weiner CP: Molecular mechanism of cGMP-mediated smooth muscle relaxation. J Cell Physiol 2000;184:409-420.

19 Feil R, Hofmann F, Kleppisch T: Function of cGMP-dependent protein kinases in the nervous system. Rev Neurosci 2005;16: 23-41.

20 Toda N, Okamura T: Modification by L-N ${ }^{G}$ monomethyl arginine (L-NMMA) of the response to nerve stimulation in isolated dog mesenteric and cerebral arteries. Jpn J Pharmacol 1990;52:170-173.

-21 Toda N, Okamura T: The pharmacology of nitric oxide in the peripheral nervous system of blood vessels. Pharmacol Rev 2003;55: 271-324.

-22 Vincent SR, Kimura H: Histochemical mapping of nitric oxide synthase in the rat brain. Neuroscience 1992;46:755-784.
23 Krukoff TL, Khalili P: Stress-induced activation of nitric oxide-producing neurons in the rat brain. J Comp Neurol 1997;377:509-519.

24 Valtschanoff JG, Weinberg RJ, Rustioni A: NADPH diaphorase in the spinal cord of rats. J Comp Neurol 1992;321:209-222.

25 Holzer P: Efferent-like roles of afferent neurons in the gut: blood flow regulation and tissue protection. Auton Neurosci 2006;125: 70-75.

26 Kiss JP, Vizi ES: Nitric oxide: a novel link between synaptic and nonsynaptic transmission. Trends Neurosci 2001;24:211-215.

27 Toda N, Okamura T: Possible role of nitric oxide in transmitting information from vasodilator nerve to cerebroarterial muscle. Biochem Biophys Res Commun 1990;170: 308-313.

28 Toda N, Okamura T: Nitroxidergic nerve: regulation of vascular tone and blood flow in the brain. J Hypertens 1996;14:423-434.

29 Bachmann S, Bosse HM, Mundel P: Topography of nitric oxide synthesis by localizing constitutive NO synthases in mammalian kidney. Am J Physiol Renal Physiol 1995; 268:F885-F898.

30 Liu L, Liu GL, Barajas L: Distribution of nitric oxide synthase-containing ganglionic neuronal somata and postganglionic fibers in the rat kidney. J Comp Neurol 1996;369: 16-30.

>31 Wu F, Park F, Cowley AW, Mattson D: Quantification of nitric oxide synthase activity in microdissected segments of the rat kidney. Am J Physiol Renal Physiol 1999;276:F874F881.

32 Vials AJ, Crowe R, Burnstock G: A neuromodulatory role for neuronal nitric oxide in the rabbit renal artery. Br J Pharmacol 1997; 121:213-220.

>33 Tamaki T, Kiyomoto K, Aki Y, Kimura S, Abe Y: Possible existence of nitroxidergic nerves in isolated rabbit afferent arterioles. J Am Soc Nephrol 1995;6:671.

34 Ichihara A, Inscho EW, Imig JD, Navar LG: Neuronal nitric oxide synthase modulates rat renal microvascular function. Am J Physiol Renal Physiol 1998;274:F516-F524.

35 Ichihara A, Imig JD, Navar LG: Neuronal nitric oxide synthase-dependent afferent arteriolar function in angiotensin II-induced hypertension. Hypertension 1999;33:462-466.

36 Ichihara A, Hayashi M, Hirota N, Saruta T: Superoxide inhibits neuronal nitric oxide synthase influences on afferent arterioles in spontaneously hypertensive rats. Hypertension 2001;37:630-634.

37 Tojo A, Onozato ML, Fukuda S, Asaba K, Kimura K, Fujita T: Nitric oxide generated by nNOS in the macula densa regulates the afferent arteriolar diameter in rat kidney. Med Electron Microsc 2004;37:236-241.
38 Pucci ML, Lin L, Nasjletti A: Pressor and renal vasoconstrictor effects of NG-nitro-Larginine as affected by blockade of pressor mechanisms mediated by the sympathetic nervous system, angiotensin, prostanoids and vasopressin. J Pharmacol Exp Ther 1992; 261:240-245.

39 Baylis C, Slangen B, Hussain S, Weaver C: Relationship between basal NO release and cyclooxygenase products in the normal rat kidney. Am J Physiol Regul Integr Comp Physiol 1996;271:R1327-R1334.

40 Tost H, Hably C, Lengyel M, Gógl A, Lendvai A, Bartha J: Effects of nitric oxide synthase inhibition on renal circulation and excretory function in anaesthetized rats. Exp Physiol 2000;85:791-800.

41 Gabbai FB: Effects of nitric oxide synthase blockers on renal function. Nephrol Dial Transplant 2001;16(suppl 1):10-13.

42 Walkowska A, Kompanowska-Jezierska E, Sadowski J: Nitric oxide and renal nerves: comparison of effects on renal circulation and sodium excretion in anesthetized rats. Kidney Int 2004;66:705-712.

43 Wang X, Cupples WA: Brown Norway rats show impaired nNOS-mediated information transfer in renal autoregulation. Can J Physiol Pharmacol 2009;87:29-36.

$>44$ Cervenka L, Kramer HJ, Maly J, Heller J: Role of nNOS in regulation of renal function in angiotensin II-induced hypertension. Hypertension 2001;38:280-285.

45 Mattson DL, Meister CJ: Renal cortical and medullary blood flow responses to L-NAME and ANG II in wild-type, nNOS null mutant, and eNOS null mutant mice. Am J Physiol Regul Integr Comp Physiol 2005;289:R991R997.

46 Patterson ME, Mullins JJ, Michell KD: Renoprotective effects of neuronal NOS-derived nitric oxide and cyclooxygenase- 2 metabolites in transgenic rats with inducible malignant hypertension. Am J Physiol Renal Physiol 2008;294:F205-F211.

47 Kihara M, Umemura S, Sugaya T, Toya Y, Yabana M, Kobayashi S, Tamura K, Kadota T, Kishida R, Murakami K, Fukamizu A, Ishii $\mathrm{M}$ : Expression of neuronal type nitric oxide synthase and renin in the juxtaglomerular apparatus of angiotensin type-1a receptor gene-knockout mice. Kidney Int 1998;53: 1585-1593.

48 Chin SY, Pandey KN, Shi SJ, Kobori H, Moreno C, Navar LG: Increased activity and expression of $\mathrm{Ca} 2+$-dependent NOS in renal cortex of ANG II-induced hypertensive rats. Am J Physiol 1999;277:F797-F804.

49 Alexander BT, Miller MT, Kassab S, Novak J, Reckelhoff JF, Kruckeberg WC, Granger JP: Differential expression of renal nitric oxide synthase isoforms during pregnancy in rats. Hypertension 1999;33:435-439. 
-50 Abram SR, Alexander BT, Bennett WA, Granger JP: Role of neuronal nitric oxide synthase in mediating renal hemodynamic changes during pregnancy. Am J Physiol Regul Integr Comp Physiol 2001;281:R1390R1393.

51 Ratliff B, Rocebaugh J, Sekulic M, Dong KW, Solhaug M: Nitric oxide synthase and reninangiotensin gene expression and NOS function in the postnatal renal resistance vasculature. Pediatr Nephrol 2009;24:355-365.

52 Kakoki M, Zou AP, Mattson DL: The influence of nitric oxide synthase 1 on blood flow and interstitial nitric oxide in the kidney. Am J Physiol Regul Integr Comp Physiol 2001;281:R91-R97.

-53 Kawasaki H, Takasaki K, Saito A, Goto K: Calcitonin gene-related peptide acts as a novel vasodilator neurotransmitter in mesenteric resistance vessels of the rat. Nature 1988;335:164-167.

54 Wakefield ID, March JE, Kemp PA, Valentin JP, Bennett T, Gardiner SM: Comparative regional haemodynamic effects of the nitric oxide synthase inhibitors, S-methyl-L-thiocitrulline and L-NAME, in conscious rats. Br J Pharmacol 2003;139:1235-1243.

>55 Moll-Kaufmann C, Sumanovski LT, Sieber CC: Neurally-mediated vasodilatation in normal and portal hypertensive rats: role of nitric oxide and calcitonin gene-related peptide. J Hepatol 1998;28:1031-1036.

56 Toda N, Ayajiki K, Okamura T: Cerebral blood flow regulation by nitric oxide: recent advances. Pharmacol Rev 2009;61:62-97.

57 Lancaster JR Jr: The physiological properties of nitric oxide: determinants of the dynamics of NO in tissues; in Ignarro LJ (ed): Nitric Oxide - Biology and Pathobiology. New York, Academic, 2000, pp 209-224.
58 Kwon O, Hong SM, Ramesh G: Diminished NO generation by injured endothelium and loss of macula densa nNOS may contribute to sustained acute kidney injury after ischemia-reperfusion. Am J Physiol Renal Physiol 2009;296:F25-F33.

59 Artune F, Essig M, Artune N, Plachtzik C Reich M, Boehmer G, Haering HU, Erley CM, Risler T: Effects of tetrahydrobiopterin on nitric oxide bioavailability and renal hemodynamics in healthyvolunteers. JNephrol 2008;21:850-860.

60 Egi Y, Matsumura Y, Murata S, Umekawa T, Hisaki K, Takaoka M, Morimoto S: The effects of $\mathrm{N}^{\mathrm{G}}$-nitro-L-arginine, a nitric oxide synthase inhibitor, on norepinephrine overflow and antidiuresis induced by stimulation of renal nerves in anesthetized dogs. J Pharmacol Exp Ther 1994;269:529-535.

61 Walkowska A, Badzynska B, KompanowskaJezierska E, Johns EJ, Sadowski J: Effects of renal nerve stimulation on intrarenal blood flow in rats with intact or inactivated NO synthases. Acta Physiol Scand 2005;183:99105.

62 Stegbauer J, Kuczka Y, Vonend O, Quack I, Sellin L, Patzak A, Steege A, Langnaese K, Rump LC: Endothelial nitric oxide synthase is predominantly involved in angiotensin II modulation of renal vascular resistance and norepinephrine release. Am J Physiol Regul Integr Comp Physiol 2008;294:R421-R428.

63 Weiss ML, Chowdhury SI, Patel KP, Kenney MJ, Huang J: Neural circuitry of the kidney: NO-containing neurons. Brain Res 2001; 919:269-282.

64 Nishida Y, Chen QH, Tandai-Hiruma M, Terada S, Horiuchi J: Neuronal nitric oxide strongly suppresses sympathetic outflow in high-salt Dahl rats. J Hypertens 2001;19: 627-634.
65 Tandai-Hiruma M, Horiuchi J, Sakamoto H, Kemuriyama T, Hirakawa H, Nishida Y: Brain neuronal nitric oxide synthase neuron-mediated sympathoinhibition is enhanced in hypertensive Dahl rats. J Hypertens 2005;23:825-834.

66 Li YF, Roy SK, Channon KM, Zucker IH, Patel KP: Effect of in vivo gene transfer of nNOS in the PVN on renal nerve discharge in rats. Am J Physiol Heart Circ Physiol 2002; 282:H594-H601.

67 Campese VM, Ye S, Zhong H: Downregulation of neuronal nitric oxide synthase and interleukin-1 $\beta$ mediates angiotensin II-dependent stimulation of sympathetic nerve activity. Hypertension 2002;39:519-524.

68 Li YF, Wang W, Mayhan WG, Patel KP: Angiotensin-mediated increase in renal sympathetic nerve discharge within the PVN: role of nitric oxide. Am J Physiol Regul Integr Comp Physiol 2006;290:R1035-R1043.

69 Zheng H, Mayhan WG, Bidasee KR, Patel KP: Blunted nitric oxide-mediated inhibition of sympathetic nerve activity within the paraventricular nucleus in diabetic rats. Am J Physiol Regul Integr Comp Physiol 2006; 290:R992-R1002.

70 Ma HJ, Cao YK, Liu YX, Wang R, Wu YM: Microinjection of resveratrol into rostral ventrolateral medulla decreases sympathetic vasomotor tone through nitric oxide and intracellular $\mathrm{Ca}^{2+}$ in anesthetized male rats. Acta Pharmacol Sin 2008;29:906-912.

71 Wei SG, Zhang ZH, Yu Y, Felder RB: Systemically administered tempol reduces neuronal activity in paraventricular nucleus of hypothalamus and rostral ventrolateral medulla in rats. J Hypertens 2009;27:543-550. 